\title{
Enhancing the quality and lipid stability of chicken nuggets using natural antioxidants
}

\author{
Muhammad Sajid Arshad ${ }^{1,2^{*}}$, Ali Imran ${ }^{1}$, Muhammad Tahir Nadeem', Muhammad Sohaib ${ }^{3}$, Farhan Saeed , \\ Faqir Muhammad Anjum ${ }^{1}$, Joong-Ho Kwon ${ }^{2}$ and Shahzad Hussain ${ }^{4}$
}

\begin{abstract}
Background: Current day consumers prefer natural antioxidants to synthetic antioxidants because they are more active. However, the activity generally depends on the specific condition and composition of food. The aim of this study was to investigate the effect of wheat germ oil and a-lipoic acid on the quality characteristics, antioxidant status, fatty acid profile, and sensory attributes of chicken nuggets.

Methods: Six types of diets were prepared for feeding the chickens to evaluate the quality of nuggets made from the leg meat of these experimental animals. These included control, diet enriched with wheat germ oil (WGO), which is a rich natural source of a-tocopherol (AT), diet with added AT or a-lipoic acid (ALA), diet with a combination of either ALA and WGO (ALA + WGO) or ALA and synthetic AT (ALA + AT). ALA has great synergism with synthetic as well as natural AT (WGO).

Results: The diet with WGO and ALA showed the best potential with respect to both antioxidant activity and total phenolic content. HPLC results revealed that the chicken nuggets made from WGO + ALA group showed maximum deposition of AT and ALA. The stability of the nuggets from control group was found to be significantly lower than that of nuggets from the WGO + ALA group. Total fatty acid content too was higher in the nuggets from this group. The poly unsaturated fatty acids (PUFA) were found to be higher in the nuggets from the groups fed with a combination of natural and synthetic antioxidants.
\end{abstract}

Conclusion: It is concluded that the combination of natural and synthetic antioxidants in the animal feed exerts a synergistic effect in enhancing the stability and quality of chicken nuggets.

Keywords: Wheat germ oil, Fatty acid, a-lipoic acid, Sensory evaluation, Chicken nuggets

\section{Background}

Using synthetic or natural antioxidants is a major strategy used to prevent lipid oxidation. The current trend in the food industry is using natural additives in preference to synthetic additives [1]. The growth of the animals and the antioxidant potential of the meat from these animals can be improved by the addition of antioxidants as dietary supplements to animal feed. The addition of natural antioxidants to animal feed enhances the lipid stability, improves the sensory attributes of meat, and improves the functionality of meat products $[2,3]$.

\footnotetext{
*Correspondence: sajid_ft@yahoo.com; msajidarshad@gcuf.edu.pk ${ }^{1}$ Institute of Home and Food Sciences, Government College University Faisalabad, Punjab, Pakistan

${ }^{2}$ School of Food Science and Biotechnology, Kyungpook National University, Daegu, South Korea

Full list of author information is available at the end of the article
}

The quality of meat increased by the addition of antioxidants in the animal feed [4]. Different types of antioxidants are added to the animal feeds for different purposes. The use of synthetic and natural antioxidants has synergistic effect on the quality as well as the antioxidant potential of meat. Wheat germ and wheat germ oil (WGO) have been used as dietary supplements for different purposes [5]. Wheat germ contains mainly protein (26-35\%), lipids (10-15\%), and minerals (4\%) and major bioactive compounds like tocopherol, policosanols, and sterols [6]. Wheat germ is the richest plant source of vitamin E. The meat quality from chickens can be improved by dietary supplementation of vitamin E, which alleviates oxidative stress [7].

WGO is also rich in essential fatty acids like linoleic acid and alpha linolenic acid. These are helpful in 
performing numerous functions like lowering the cholesterol level, and enhancing endurance. WGO also stimulates the tocopherol redox-system by changing the lipid peroxidation [8]. In addition to vitamin $\mathrm{E}$ and essential fatty acids, WGO also contain Vitamin B complex and is important for chemoprevention [8]. WGO, because of its vitamin $\mathrm{E}$ content, protects cells against free radicals, which negatively impact the metabolism.

ALA, widely distributed in many foods, is a short chain fatty acid and is a powerful natural antioxidant [9]. ALA is not only an antioxidant but also a co-factor for many enzymes. ALA stimulates glucose oxidation in muscles and improves insulin sensitivity. It is also helpful to reduce the oxidative stress in tissues of different mammals [10]. The antioxidant potential of both ALA and AT is helpful in reducing lipid oxidation in both raw and processed chicken meat and meat products $[11,12]$. Antioxidants in chicken meat also reduce drip loss by lowering the post mortem $\mathrm{pH}$ of the meat [13].

The aim of the present project was to investigate the antioxidant potential of different natural antioxidants and their effect on the stability, sensory attributes, and fatty acid profile of chicken nuggets made from the meat of animals fed with different antioxidants individually or in combination.

\section{Methods}

\section{Procurement of raw materials}

All the chemicals and reagents required for the study were purchased from Sigma Aldrich (Tokyo, Japan) and Merck (Merck KGaA, Darmstadt, Germany). This research project was conducted at the National Institute of Food Science and Technology (NIFSAT) and Nutrition Research Center, University of Agriculture, Faisalabad, Pakistan. The experimental design included 6 different diets supplemented with various antioxidants, singly or in combination; control, WGO, AT, ALA, WGO + ALA and AT + ALA. Chicken nuggets were made from the leg portion of chickens fed with these diets.

\section{Chicken nugget preparation and processing}

Antioxidant enriched chicken meat was used for the preparation of nuggets by following the method described by Perlo et al. [14]. The nuggets were stored for 45 days at $-18{ }^{\circ} \mathrm{C}$ and analysis was done at 15 -day intervals. The raw material for manufacturing the nuggets was weighed and cleaned according to the recipe. The recipe for the preparation of nuggets is as follows. Boneless chicken (500 g), Egg (1), oil (as required for frying), black pepper (12 g), garlic paste (1 tsp), onion (1), plain flour (120 g), bread crumbs (70 g), and salt (20 g). The control and antioxidant enriched broiler meat (leg) were washed multiple times with tap water, deboned manually and minced using an electric mincer to very fine consistency for preparing nuggets of excellent texture. The minced meat and onions were mixed in a meat mixer for $5 \mathrm{~min}$, followed by the addition of all other ingredients according to the recipe and mixed using a meat mixer to obtain a uniform blend. When all the ingredients were thoroughly mixed, the mixture was spread into a thin layer (10 $\mathrm{mm}$ thickness) and shaped into discs of $30 \mathrm{~mm}$ diameter $(10 \pm 1 \mathrm{~g} /$ piece). The nuggets were dipped sequentially in plain flour and bread crumbs and fried in canola oil at $180{ }^{\circ} \mathrm{C}$ till golden brown in color.

\section{Antioxidant status of chicken nuggets}

The antioxidant status of the chicken nuggets was determined by different methods described below. The total phenolic content (TPC) in the nuggets was determined by adopting the procedure described by Senevirathne et al. [15]. The total phenolic content of the nuggets was estimated as gallic acid equivalent (mg GAE/100 g). The nugget samples were subjected to 2,2- diphenyl-1picrylhydrazyl (DPPH) radical scavenging activity analysis according to the procedure outlined by Brand-Williams et al. [16]. Percentage neutralization of free radicals was assayed using DPPH and calculated using the following formula. \% Neutralization $=100 \times\left(\mathrm{A}_{\text {blank }}-\mathrm{A}_{\text {sample }} / \mathrm{A}_{\text {blank }}\right) . \mathrm{ABTS}^{+}$reducing activity of the nugget samples was measured using the method described by Erel [17]. $\mathrm{ABTS}^{+}$reducing activity $(\%)=\left[\left(\mathrm{A}_{\text {control }}-\mathrm{A}_{\text {sample }}\right) \div \mathrm{A}_{\text {control }}\right] \times 100$. The ferric reducing antioxidant power (FRAP) in the nugget samples was estimated using the method described by Arshad et al. [18] with some modification.

\section{Physico-chemical analysis of nuggets}

$\mathrm{pH}$ of the nuggets was measured with a $\mathrm{pH}$ meter according to the method described by Sallam et al. [19]. Ten grams of the sample was homogenized with $50 \mathrm{~mL}$ distilled water and $\mathrm{pH}$ was measured using a digital $\mathrm{pH}$ meter. A hand-held tristimulus colorimeter (Color Test Meter II) was used to determine the color of the nuggets at regular storage intervals $(0,15,30$, and 45 days) by following the procedure described by Elgasim and Al-Wesali [20]. Color was determined by placing the nuggets in a petri plate under a photocell. The water content of the nuggets was measured using electronic Hygropalm water activity meter (Model Aw-Win, Rotronic, equipped with a Karl-Fast probe) at regular storage intervals, using the method described by Cosenza et al. [21]. The textural characteristics of nuggets were measured at different storage intervals by using a texture analyzer (Mod. TA-XT2, Stable Microsystems, surrey, UK) as described by Cardoso et al. [22]. The nuggets were fried and compression test was performed to check the texture of the product. 


\section{Lipid stability analysis}

The lipid stability of chicken nuggets was determined in terms of the amounts of thiobarbituric acid-reactive substances (TBARS) and peroxide value (POV). The amount of TBARS in the nuggets was estimated as per the guidelines of Liu et al. [23] and TBARS was expressed as milligrams of malondialdehyde (MDA)/kg meat. The POV of the nuggets was determined by the method outlined by Shantha and Decker [24] and expressed as meq peroxide $/ \mathrm{kg}$.

\section{Quantification of $a$-lipoic acid and a-tocopherol}

The ALA content in the nugget samples was measured according to the method described by Satoh et al. [25] with some modifications. The nugget samples were prepared according to the method described by Asghar et al. [26] for the determination of AT. HPLC chromatograms were obtained by using a C18 column, $(250 \mathrm{~mm} \times 4.6 \mathrm{~mm}, 5.0 \mu \mathrm{m})$, System controller SCL-10 A, water pump LC-10 AT, and flow controller valve FCV-10 AL with a mobile phase of $100 \%$ methanol at a flow rate of $1 \mathrm{~mL} / \mathrm{min}$.

\section{Fatty acid Profile}

Total fatty acids were extracted from nugget samples per the method described by Folch et al. [27]; this method uses an antioxidant to prevent oxidation during sample preparation and a flame ionization detector (FID). The injector temperature was $250{ }^{\circ} \mathrm{C}$ and the detector temperature was $300{ }^{\circ} \mathrm{C}$. The column temperature program initiated the runs at $100{ }^{\circ} \mathrm{C}$ for $2 \mathrm{~min}$, warmed to $170{ }^{\circ} \mathrm{C}$ at $10^{\circ} \mathrm{C} / \mathrm{min}$, held for $2 \mathrm{~min}$, warmed to $220^{\circ} \mathrm{C}$ at $7.5^{\circ} \mathrm{C} / \mathrm{min}$ and then again held for $20 \mathrm{~min}$ to facilitate optimal separation. Results are presented as percentage of total fatty acids.

\section{Sensory evaluation}

Sensory evaluation of the nuggets was carried out by a trained panel at different storage intervals $(0,15,30$, and 45 days), using a 9-point hedonic scale $(9=$ like extremely; 1 = dislike extremely), as per the guidelines of Meilgaard et al. [28]. Sensory assessment for various quality attributes of nuggets, such as appearance, flavor, taste, and overall acceptability, were recorded. All evaluations were conducted by panelists trained in sensory evaluation of foods made from muscle meat. The panelists carried out the evaluation in individual booths under clear white fluorescent light in the Sensory Evaluation Laboratory of NIFSAT, University of Agriculture, Faisalabad, Pakistan. During the evaluation process, the panelists were provided unsalted crackers, mineral water, and expectorant cups to neutralize and rinse their taste receptors between different samples to facilitate rational assessment. The descriptors were rated on a scale from "0" representing the lowest score and " 9 " the highest. The panelists were requested to rate the product quality by scoring for the selected parameters.

\section{Statistical analysis}

The work was carried out using completely randomized design (CRD), and the data obtained for different parameters was analyzed statistically using the Statistical Package, Statistic 8.1. Levels of significance $(P \leq 0.05)$ were determined (ANOVA) using 2-factor factorial CRD by following the principles outlined by Steel and Torrie [29]. The means were compared using LSD.

\section{Results and Discussions}

\section{Antioxidant potential of chicken nuggets}

The stable nitrogen radical having yellow color is a DPPH radical and it can be easily solubilized in organic solvents [30]. The metastable radical having blue color is the ABTS radical and dissolves easily in water as well as organic solvents [31]. The results showed that the nuggets from different diet fed animals had significant antioxidant parameters like DPPH, FRAP, ABTS and TPC at all storage intervals as shown in Fig. 1. The group containing a combination of ALA and WGO showed maximum percentage inhibition DPPH (79.24\%) and ABTS (37.44\%), whereas the percentage inhibition DPPH (67.35\%) and ABTS (21.67\%) were lowest in control group at 0 day of storage. The DPPH free radical scavenging activity and ABTS decreased as the storage duration increased. The group having WGO + ALA displayed higher free radical scavenging activity (71.26\%) and ABTS (29.65\%) on the 45th day of storage compared to that of control (59.37\% and 15.48\%). The results showed that the antioxidant activity of chicken nuggets was more in the group containing natural antioxidants compared to that of other groups. These results are in accordance with the findings of Arshad et al. $[18,32]$ who speculated that the antioxidant activity of raw and cooked chicken meat was higher when the animals were fed with a diet containing antioxidants that act synergistically. The results are further supported by Jung et al. [33] and Selim et al. [34] who showed that chicken meat from animals fed with dietary natural antioxidants has more antioxidant activity compared to that from control diet fed animals.

The group with combination of ALA and WGO showed maximum antioxidant power $\left(637.56 \mu \mathrm{mol} / \mathrm{Fe}^{+2} / \mathrm{g}\right.$ meat $)$ and TPC (140.92 mg GAE/100 g meat) compared to those in the control $\left(571.93 \mu \mathrm{mol} / \mathrm{Fe}^{+2} / \mathrm{g}\right.$ meat) and TPC (99.02 mg GAE/100 g meat) at 0 day of storage. The ferric reducing antioxidant power and TPC decreased as the storage intervals increased. FRAP $\left(624.84 \mu \mathrm{mol} / \mathrm{Fe}^{+2} / \mathrm{g}\right.$ meat) and TPC (87.62 mg GAE/100 g meat) were higher 

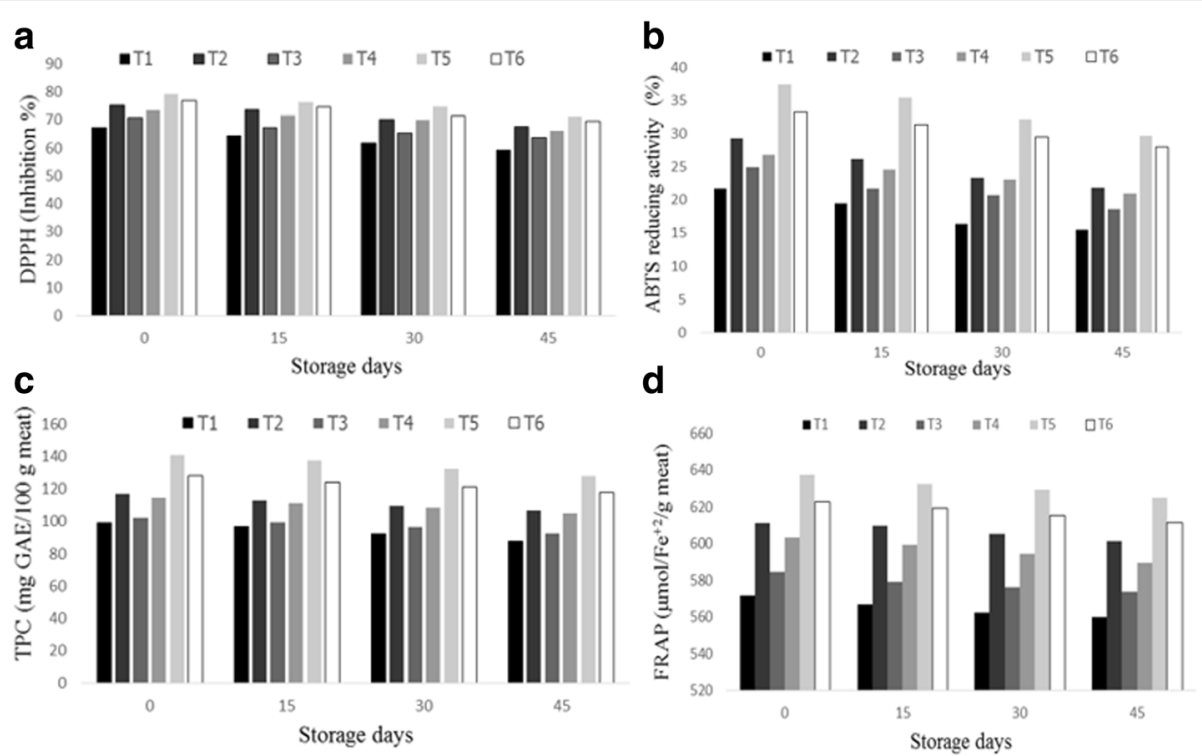

Fig. 1 (a-d): (a) DPPH free radical scavenging activity of the chicken nuggets (b) ABTS reducing activity of the nuggets (c) Total phenolic contents of the nuggets (d) FRAP of the nuggets

at 45th day of storage in nuggets from the group fed with WGO + ALA, whereas the values were lower in control group $\left(559.67 \mu \mathrm{mol} / \mathrm{Fe}^{+2} / \mathrm{g}\right.$ meat and $87.62 \mathrm{mg} \mathrm{GAE} /$ $100 \mathrm{~g}$ meat). Different studies proved that there was positive correlation between the antioxidant activities and total phenolic contents in raw and cooked chicken meat $[11,35-37]$. The results showed that the antioxidant potential was higher in the meat from the group fed with both natural antioxidant (WGO) and ALA. This finding is consistent with those of Mancini et al. [38], who speculated that by using antioxidants like turmeric and ascorbic acid, the antioxidant potential (DPPH, ABTS and FRAP) in rabbit burgers could be increased compared to that of the control where no antioxidants were used during storage. Banerjee et al. [39] showed that goat meat enriched with natural antioxidants showed higher FRAP and DPPH values than those of the control.

\section{Physico-chemical properties of chicken nuggets}

One of the important physical factors in the postmortem stage is $\mathrm{pH}$. Many other factors such as cooking loss and color also affect the different sensory parameters [40]. Our results showed that different diets and storage intervals had significant effect on the $\mathrm{pH}$ and color of the nuggets as shown in Table 1 . The results showed that the nuggets from the group which had the combination of ALA and WGO had significantly higher $\mathrm{pH}$ (6.47) and color (102 CTn) on the 45th day of storage, whereas those from control group of animals had the lowest $\mathrm{pH}$ (5.86) and color (92 CTn). pH showed a trend of increasing with increasing duration of storage. Our results are consistent with those of Chidanandaiah et al. [41], who reported that the $\mathrm{pH}$ of buffalo meat patties increased with the duration of storage. Jay [42] reported that the increase in $\mathrm{pH}$ during storage might be due to

Table $1 \mathrm{pH}$ and color of the chicken leg meat nuggets

\begin{tabular}{|c|c|c|c|c|c|c|c|c|c|c|}
\hline \multirow[t]{2}{*}{ Treatments } & \multicolumn{5}{|c|}{$\mathrm{pH}$ of leg nuggets with storage days } & \multicolumn{5}{|c|}{ Color of leg nuggets with storage days } \\
\hline & 0 & 15 & 30 & 45 & Mean & 0 & 15 & 30 & 45 & Mean \\
\hline Control & 5.76 & 5.8 & 5.83 & 5.86 & $5.81 e$ & 104 & 100 & 96 & 92 & $98 \mathrm{e}$ \\
\hline WGO & 5.92 & 5.96 & 6 & 6.03 & $5.98 \mathrm{c}$ & 112 & 107 & 102 & 99 & $105 b$ \\
\hline AT & 5.84 & 5.86 & 5.91 & 5.94 & $5.89 d$ & 107 & 102 & 98 & 94 & $100 d$ \\
\hline ALA & 5.92 & 5.94 & 5.98 & 6.05 & $5.97 \mathrm{c}$ & 110 & 104 & 101 & 98 & $103 c$ \\
\hline WGO + ALA & 6.34 & 6.38 & 6.42 & 6.47 & $6.4 a$ & 116 & 110 & 106 & 102 & $109 a$ \\
\hline $\mathrm{WGO}+\mathrm{AT}$ & 6.08 & 6.1 & 6.16 & 6.21 & $6.14 b$ & 113 & 108 & 103 & 100 & $106 \mathrm{~b}$ \\
\hline Mean & $5.98 d$ & $6.01 \mathrm{c}$ & $6.05 b$ & $6.09 a$ & & $110 a$ & $105 b$ & $101 \mathrm{c}$ & $98 d$ & \\
\hline
\end{tabular}

The results are mean of three independent measurements. Means sharing of the similar letter are statistically non-significant $(P>0.05)$ in a row or in a column Control, WGO = (wheat germ oil (Natural a-tocopherol) $200 \mathrm{mg} / \mathrm{kg}$ feed), AT (a-tocopherol $200 \mathrm{mg} / \mathrm{kg}$ feed), ALA = a-Lipoic acid $150 \mathrm{mg} / \mathrm{kg}$ feed,

$\mathrm{WGO}+\mathrm{ALA}=$ wheat germ oil (Natural a-tocopherol) $200 \mathrm{mg} / \mathrm{kg}$ feed) $+\mathrm{a}$-Lipoic acid $150 \mathrm{mg}, \mathrm{ALA}+\mathrm{AT}=\mathrm{a}$-Lipoic acid $150 \mathrm{mg}+\mathrm{a}$-tocopherol $200 \mathrm{mg} / \mathrm{kg}$ feed 
the fact that on meat and meat products, there is an accumulation of metabolites of bacterial action and deamination of meat proteins. The results are further supported by Sureshkumar et al. [43] who found that $\mathrm{pH}$ of buffalo meat sausages increased on storage and Kumar and Tanwar [44] who reported an increase in the $\mathrm{pH}$ of chicken nuggets on storage. The color value of chicken nuggets decreased during storage while higher color value was observed in groups benefiting from the synergism of antioxidants. The results are in agreement with the findings of Chandralekha et al. [45] who reported that the color value of chicken meat balls supplemented with natural antioxidants was higher than that of the groups receiving other treatments. They also reported a decrease in the color value during storage, which was a result of oxidation. These results were further supported by the study of Kala et al. [46] who showed that the color value of chicken patties decreased during storage, but increased when they contained antioxidants. Arshad et al. [32] recently confirmed that the $\mathrm{pH}$ value of meat increased and color value decreased with storage when there was no antioxidants supplemented in the feed, but increased with storage when enriched with antioxidants.

Water activity and texture values of the chicken nuggets are presented in Table 2. These results showed that the water activity and texture of the nuggets varied significantly with different diets and storage intervals. It is evident from Table 2 that the group fed with the combination of ALA and WGO showed significantly higher water activity (0.863) and lower texture value (1119) than those of the control (water activity: 0.813 and texture: 1139) on 0 day of storage. On the 45 th day of storage, the group that was fed with the combination of ALA and WGO depicted higher water activity (0.783) and lowest texture value (1131), compared to the control group (water activity: 0.737 and texture: 1154).

The results showed that the water activity in chicken nuggets from the control decreased whereas the shear force value for texture increased during storage. There was increased water activity in chicken nuggets from the group fed with antioxidants. Sohaib et al. [11] reported that the water activity was higher and shear force value for texture was lower in antioxidant enriched chicken nuggets. Water activity tended to decrease and texture value tended to increase with storage. These results were also supported by the Arshad et al. [32]. Malav et al. [47] speculated that the decrease in shear force value observed in mutton patties enriched with antioxidant was due to the reduction in compactness because of the higher moisture content and aeration that lowers the shear force. The shear force value increased during storage because of the myofibrillar protein oxidation and the resultant increase in cross-linking and aggregation in meat $[48,49]$.

\section{Thiobarbituric acid reactive substances and peroxide value of the chicken nuggets}

Lipid oxidation is a vital phenomenon that determines the quality of meat and meat products because of its effect on protein oxidation and discoloration of the meat. Lipid oxidation during storage is also the cause of rancidity and the consequent bad odor in meat and meat products [50]. The results of the lipid oxidation analysis by using the TBARS and POV parameters are shown in Table 3. TBARS and POV of the nuggets varied significantly with the type of diet and duration of storage. Higher TBARS $(0.55 \mathrm{mg} \mathrm{MDA} / \mathrm{kg}$ ) and POV (0.91 meq peroxide $/ \mathrm{kg}$ ) values were observed on the 45 th day of storage in nuggets from control of animals, which were fed basal diet. TBARS $(0.37 \mathrm{mg} \mathrm{MDA} / \mathrm{kg})$ and POV (0.74 meq peroxide $/ \mathrm{kg}$ ) values of the nuggets were lower when the diet of the chickens was supplemented with the combination of ALA and WGO. This is in agreement with the findings of Al-Hijazeen et al. [50] who reported that the meat from chickens fed with antioxidant supplemented diet showed reduced TBARS value compared to that from control. They also speculated that

Table 2 Water activity and texture of the leg chicken nuggets during storage

\begin{tabular}{|c|c|c|c|c|c|c|c|c|c|c|}
\hline \multirow[t]{2}{*}{ Treatments } & \multicolumn{5}{|c|}{ Water activity } & \multicolumn{5}{|c|}{ Texture } \\
\hline & 0 & 15 & 30 & 45 & Mean & 0 & 15 & 30 & 45 & Mean \\
\hline Control & 0.813 & 0.787 & 0.763 & 0.737 & $0.775 d$ & 1139 & 1144 & 1150 & 1154 & $1147 a$ \\
\hline WGO & 0.843 & 0.813 & 0.793 & 0.763 & $0.803 c$ & 1129 & 1134 & 1137 & 1143 & $1136 c$ \\
\hline AT & 0.833 & 0.803 & 0.78 & 0.753 & $0.793 \mathrm{~cd}$ & 1139 & 1140 & 1146 & 1150 & $1144 b$ \\
\hline ALA & 0.84 & 0.81 & 0.79 & 0.76 & $0.8 \mathrm{c}$ & 1133 & 1135 & 1139 & 1145 & $1138 \mathrm{bc}$ \\
\hline$W G O+A L A$ & 0.863 & 0.84 & 0.82 & 0.783 & $0.827 a$ & 1119 & 1123 & 1127 & 1131 & $1125 d$ \\
\hline$W G O+A T$ & 0.853 & 0.823 & 0.803 & 0.773 & $0.813 b$ & 1125 & 1131 & 1136 & 1141 & $1133 c$ \\
\hline Mean & $0.841 a$ & $0.813 b$ & $0.792 \mathrm{C}$ & $0.762 d$ & & 1131d & $1135 c$ & $1139 b$ & $1144 a$ & \\
\hline
\end{tabular}

The results are mean of three independent measurements. Means sharing of the similar letter are statistically non-significant $(P>0.05)$ in a row or in a column Control, WGO = (wheat germ oil (Natural a-tocopherol) $200 \mathrm{mg} / \mathrm{kg}$ feed), AT (a-tocopherol $200 \mathrm{mg} / \mathrm{kg}$ feed), ALA = a-Lipoic acid $150 \mathrm{mg} / \mathrm{kg}$ feed 
Table 3 Thiobarbituric acid reactive substances and peroxide value of the leg chicken nuggets during storage

\begin{tabular}{|c|c|c|c|c|c|c|c|c|c|c|}
\hline \multirow[t]{2}{*}{ Treatments } & \multicolumn{5}{|c|}{ TBARS (mg MDA/kg) } & \multicolumn{5}{|c|}{ POV (meq peroxide/kg) } \\
\hline & 0 & 15 & 30 & 45 & Mean & 0 & 15 & 30 & 45 & Mean \\
\hline Control & 0.37 & 0.43 & 0.48 & 0.55 & $0.46 a$ & 0.75 & 0.79 & 0.85 & 0.91 & $0.83 a$ \\
\hline WGO & 0.27 & 0.31 & 0.36 & 0.41 & $0.34 c$ & 0.63 & 0.68 & 0.74 & 0.78 & $0.71 \mathrm{c}$ \\
\hline AT & 0.31 & 0.36 & 0.41 & 0.45 & $0.38 \mathrm{~b}$ & 0.68 & 0.72 & 0.76 & 0.82 & $0.75 b$ \\
\hline ALA & 0.28 & 0.33 & 0.37 & 0.42 & $0.35 c$ & 0.64 & 0.70 & 0.75 & 0.80 & $0.72 \mathrm{C}$ \\
\hline WGO + ALA & 0.22 & 0.27 & 0.32 & 0.37 & $0.30 \mathrm{e}$ & 0.59 & 0.64 & 0.68 & 0.74 & $0.66 \mathrm{~d}$ \\
\hline$W G O+A T$ & 0.25 & 0.29 & 0.34 & 0.4 & $0.32 d$ & 0.61 & 0.67 & 0.71 & 0.78 & $0.69 \mathrm{~cd}$ \\
\hline Mean & $0.28 \mathrm{~d}$ & $0.33 c$ & $0.38 b$ & $0.43 a$ & & $0.65 d$ & $0.70 c$ & $0.75 b$ & $0.81 a$ & \\
\hline
\end{tabular}

The results are mean of three independent measurements. Means sharing of the similar letter are statistically non-significant $(P>0.05)$ in a row or in a column Control, WGO = (wheat germ oil (Natural a-tocopherol) $200 \mathrm{mg} / \mathrm{kg}$ feed), AT (a-tocopherol $200 \mathrm{mg} / \mathrm{kg}$ feed), ALA = a-Lipoic acid $150 \mathrm{mg} / \mathrm{kg}$ feed,

WGO + ALA = wheat germ oil (Natural a-tocopherol) $200 \mathrm{mg} / \mathrm{kg}$ feed) + a-Lipoic acid $150 \mathrm{mg}, \mathrm{ALA}+\mathrm{AT}=\mathrm{a}$-Lipoic acid $150 \mathrm{mg}+\mathrm{a}$-tocopherol $200 \mathrm{mg} / \mathrm{kg}$ feed

there was greater increase in TBARS values during storage in cooked meat than in the raw meat. Arshad et al. [18] also reported that raw chicken meat displayed lower TBARS value compared to that of the chicken nuggets made from animals fed with the same diet. Khan et al. [12] reported that the nuggets from chickens fed diet rich in ALA and AT showed lower POV as compared to nuggets from control, which is supported by the results of our present study, where nuggets from WGO and ALA enriched group had minimum POV compared to those from other groups. Furthermore, different researchers speculated that the chicken breast nuggets supplemented with natural and synthetic antioxidants showed the lowest TBARS value, which supports the findings of the current study $[3,32]$.

\section{a-Lipoic acid and a-tocopherol contents}

ALA is both fat and water soluble in nature, scavenges the free radicals and also has the ability to regenerate other antioxidants like AT and ascorbic acid. ALA also acts as a coenzyme in different pathways of carbohydrate metabolism [9, 35]. The results of the quantification of ALA and AT by HPLC in leg nuggets are shown in Fig. 2. These results showed that the content of ALA and AT varied significantly with the type of diet. As evident from Fig. 2, the group that benefited from the synergism between WGO and ALA showed the best results not only for ALA (36.77 mg/g) but also for AT $(21.47 \mathrm{mg} / \mathrm{g})$. Nuggets from the group that was fed only basal diet contained much lower quantities of both ALA $(6.14 \mathrm{mg} / \mathrm{g}$ ) and AT $(7.63 \mathrm{mg} / \mathrm{g})$. The results are in agreement with the findings of Yasin et al. [36] and Parveen et al. [37] who speculated that the chickens whose diet was supplemented with higher quantities of ALA (150 mg/Kg) showed higher content of ALA and AT deposited in the raw meat. Khan et al. [12] also supported the idea of the synergism between ALA and AT because ALA regenerates some other antioxidants as mentioned above.

\section{Fatty acid profile of chicken leg nuggets}

The contents of individual fatty acids, saturated fatty acids (SFA), monounsaturated fatty acids (MUFA), polyunsaturated fatty acids (PUFA), unsaturated fatty acid (UFA) and the ratios of SFA/UFA and PUFA/SFA in chicken nuggets were affected by different diets as shown in Table 4. A total of 9 fatty acids were detected in the nuggets. Oleic acid $\left(C_{18: 1}\right)$ was found to be in higher quantities compared to all the other fatty acids. The content of oleic acid was significantly higher $(35.29 \%)$ in the nuggets from chickens fed with WGO supplemented diet and lowest (32.55\%) was found in group where combination of AT and ALA given to the diet of chicken. Margaric acid $\left(\mathrm{C}_{17: 0}\right)$ was present in the lowest quantity compared to all the other fatty acids. Palmitic acid $\left(C_{16: 0}\right)$ was found to be the next highest after oleic acid and its content ranged from 17.11 to 22.34\%. The MUFA (38.23\%) and PUFA (24.31\%) were also higher in the nuggets from the group fed with WGO and lowest in the nuggets from the group fed with WGO + AT. The ratio of PUFA and SFA is also very important and this ratio ranged from 0.65 to 0.69 in the nuggets made from the groups fed with different diets with no significant difference among the different

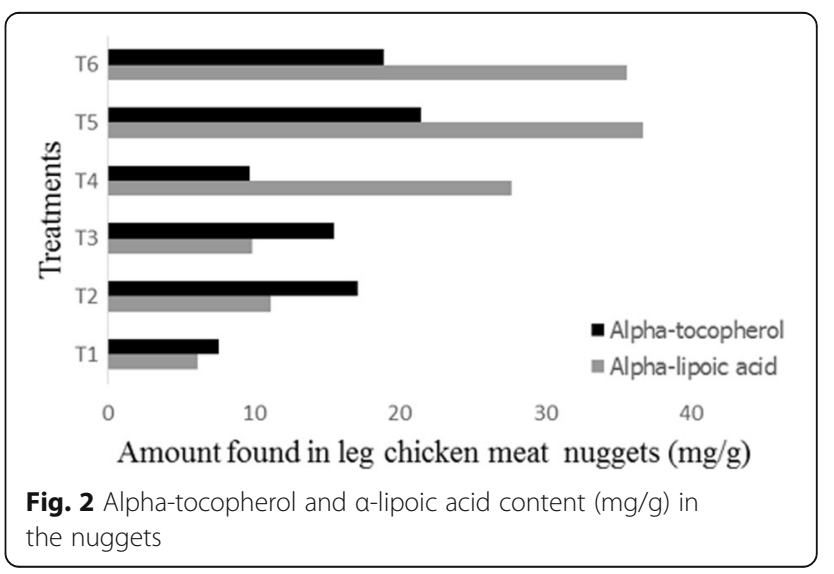


Table 4 Fatty acid composition and profile in chicken nuggets

\begin{tabular}{|c|c|c|c|c|c|c|c|}
\hline & & Control & WGO & AT & ALA & WGO + ALA & $W G O+A T$ \\
\hline \multirow[t]{9}{*}{ fatty acids (\%) in leg chicken nuggets } & ${ }^{1} C_{16: 0}$ & 18.93 & 22.34 & 18.74 & 17.97 & 21.18 & 17.11 \\
\hline & ${ }^{2} C_{16: 1}$ & 2.46 & 2.56 & 2.43 & 2.41 & 2.49 & 2.41 \\
\hline & ${ }^{3} C_{17: 0}$ & 0.51 & 0.51 & 0.49 & 0.49 & 0.50 & 0.47 \\
\hline & ${ }^{4} C_{17: 1}$ & 0.38 & 0.38 & 0.37 & 0.35 & 0.37 & 0.35 \\
\hline & ${ }^{5} C_{18: 0}$ & 13.05 & 13.37 & 12.91 & 12.61 & 13.06 & 12.35 \\
\hline & ${ }^{6} \mathrm{C}_{18: 1}$ & 33.37 & 35.29 & 33.06 & 32.78 & 35.15 & 32.55 \\
\hline & ${ }^{7} \mathrm{C}_{18: 2}$ & 14.09 & 16.41 & 13.80 & 13.57 & 16.07 & 13.28 \\
\hline & ${ }^{8} C_{18: 3}$ & 0.83 & 1.57 & 0.82 & 0.80 & 1.50 & 0.77 \\
\hline & ${ }^{9} \mathrm{C}_{20: 4}$ & 6.32 & 6.33 & 6.29 & 6.21 & 6.31 & 6.15 \\
\hline \multirow[t]{6}{*}{ fatty acid profile (\%) in leg chicken nuggets } & SFA & 32.48 & 36.22 & 32.13 & 31.06 & 34.74 & 29.93 \\
\hline & MUFA & 36.20 & 38.23 & 35.86 & 35.55 & 38.01 & 35.31 \\
\hline & PUFA & 21.24 & 24.31 & 20.91 & 20.58 & 23.88 & 20.20 \\
\hline & UFA & 57.43 & 62.53 & 56.77 & 56.13 & 61.88 & 55.51 \\
\hline & SFA/UFA & 0.57 & 0.58 & 0.57 & 0.55 & 0.56 & 0.54 \\
\hline & PUFA/SFA & 0.65 & 0.67 & 0.65 & 0.66 & 0.69 & 0.67 \\
\hline
\end{tabular}

${ }^{1}$ Palmitic ${ }^{2}$ Palmitoleic ${ }^{3}$ Margaric ${ }^{4}$ Margaroleic ${ }^{5}$ Stearic ${ }^{6}$ Oleic ${ }^{7}$ Linoleic ${ }^{8}$ Linolenic ${ }^{9}$ Arachidonic

Control, WGO = (wheat germ oil (Natural a-tocopherol) $200 \mathrm{mg} / \mathrm{kg}$ feed), AT (a-tocopherol $200 \mathrm{mg} / \mathrm{kg}$ feed), ALA = a-Lipoic acid $150 \mathrm{mg} / \mathrm{kg}$ feed

WGO + ALA = wheat germ oil (Natural a-tocopherol) $200 \mathrm{mg} / \mathrm{kg}$ feed) + a-Lipoic acid $150 \mathrm{mg}$, ALA + AT = a-Lipoic acid $150 \mathrm{mg}+\mathrm{a}$-tocopherol $200 \mathrm{mg} / \mathrm{kg}$ feed

SFA Saturated fatty acids, MUFA Mono unsaturated fatty acids, PUFA Poly unsaturated fatty acids, UFA Unsaturated fatty acids, SFA/UFA Ratio of saturated fatty

acids and unsaturated fatty acids, PUFA/SFA Ratio of poly unsaturated fatty acids and saturated fatty acids

groups. Our results are in agreement with the outcomes of Nkukwana et al. [51], who reported that there was no significant difference in the ratio of PUFA to SFA, which ranged from 0.68 to 0.82 in the meats of the animals receiving different antioxidant treatments. The recommended ratio for PUFA/SFA was around 4 [52]. Significantly higher PUFA/SFA ratio was found in broiler meat of animals fed with plant-based diet and showed higher PUFA levels [53]. The results were further supported by Arshad et al. [54] who speculated that the content of polyunsaturated fatty acids was higher in groups where the diet was supplemented with WGO.

\section{Sensory evaluation of chicken nuggets during storage}

The results of the sensory analysis of attributes like appearance, flavor, taste, and overall acceptability of the chicken nuggets are given in Fig. 3. The sensory scores given by the panel of judges to appearance, flavor, taste

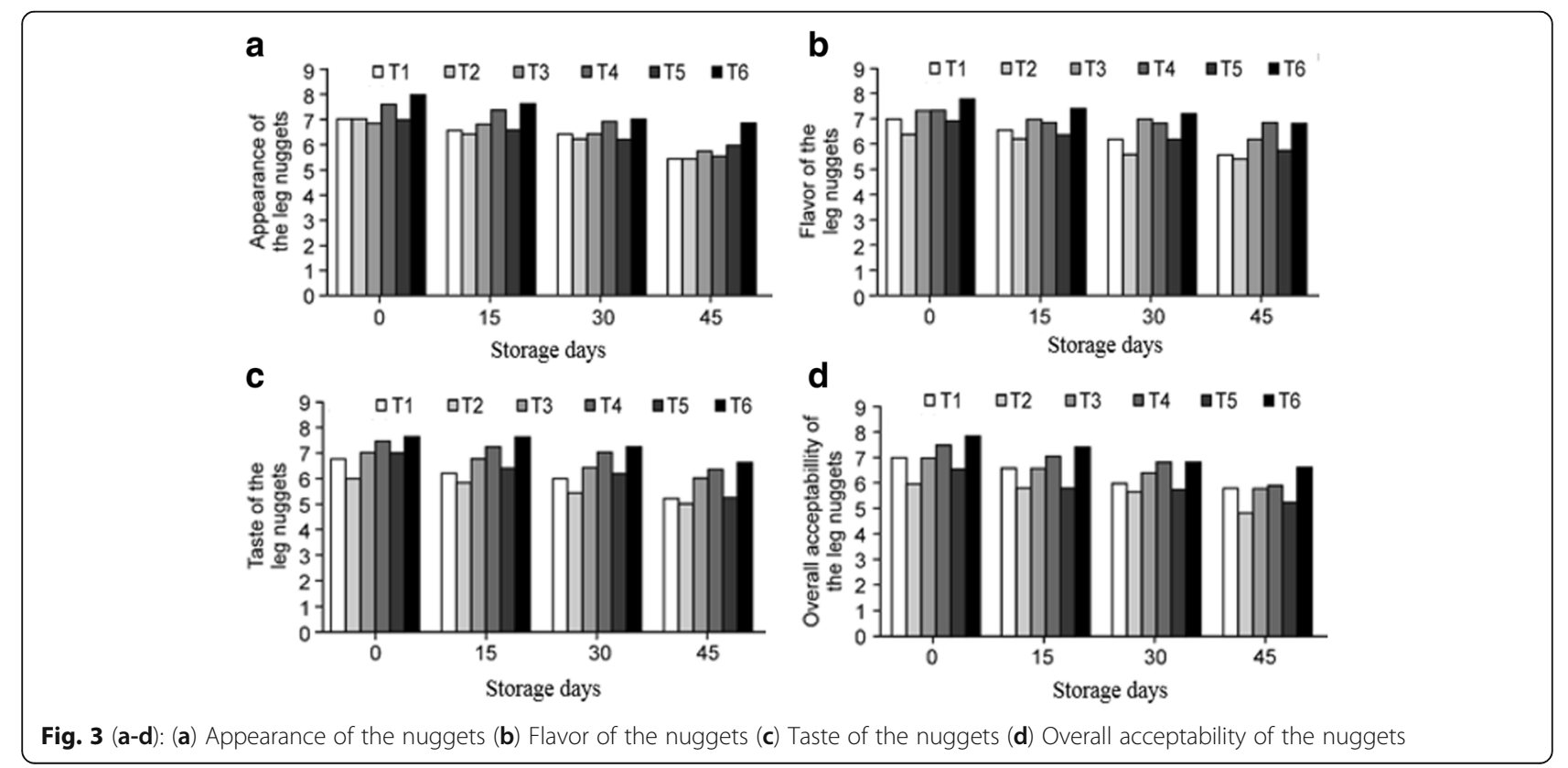


and overall acceptability varied significantly between the nuggets from the different diet groups and storage intervals. The results showed that chicken nuggets made from chickens that were fed the combination of AT and ALA scored higher for all attributes on the 45th day of storage whereas the nuggets made from WGO-fed chickens scored lower but within the acceptable limits.

It is evident from Fig. 3 that the sensory score given by the panel of judges decreased as the storage interval increased. This result is in agreement with the results of many other researchers; the appearance and color of different meat products diminished as the storage interval increased $[55,56]$. Other researchers have reported that the panel of judges had a better sensory perception of the nuggets enriched in natural antioxidants [57]. The score for flavor also decreased with storage due to the loss of volatile flavoring compounds during storage. This hypothesis was supported by Thomas et al. [58] and Bhat et al. [59]. The overall acceptability also decreased during storage because of the decline in the sensory score of other parameters like appearance, flavor, and taste. This decrease in overall acceptability was confirmed by the results of Malav et al. [60] who reported that the overall acceptability of mutton patties decreased during storage.

\section{Conclusions}

It is concluded that the chicken nuggets made from the leg meat of chickens fed with diet supplemented with both WGO and ALA have better antioxidant potential as well as stability during storage. Nuggets from the group of animals fed with WGO supplemented diet showed better fatty acid profile because of the higher PUFA content in WGO. It is believed that ALA regenerates other antioxidants like AT and ascorbic acid. Therefore, nuggets from the group fed with diet containing WGO + ALA had higher content of ALA and AT because of the synergism between ALA and AT. Regarding the descriptive sensory evaluation, the overall acceptability of chicken nuggets from the animals fed with both ALA and AT was the highest according to the scores awarded by the panelists. However, this score decreased on storage.

\section{Acknowledgements}

The authors are thankful to Higher Education Commission (HEC), Govt. of Pakistan for providing financial support for this study under HEC Ph.D. indigenous fellowship program. We also extend our thanks to Directorate of Poultry Research Farm, University of Agriculture Faisalabad (UAF), Pakistan, for the use of the broiler rearing facility. The authors also extend their appreciation to the International Scientific Partnership Program (ISPP) at King Saud University, for funding this research work through ISPP\# 0023.

\section{Funding}

The project was funded by Higher Education Commission, Islamabad, Pakistan.

\section{Availability of data and materials}

All data presented in the manuscript.

\section{Authors' contributions}

The contribution of each of the authors for this work was as follows. MSA carried out the research and prepared the manuscript. FMA helped in planning and executing the research. MS, FS, Al, MTN and SH helped in the manuscript preparation and provided the statistical skills. JHK reviewed the manuscript. All authors read and approved the final manuscript.

\section{Competing interests}

The authors have no competing interests. The authors are solely responsible for the content and writing of this manuscript.

\section{Consent for publication}

Not applicable.

Ethics approval and consent to participate Not applicable.

\section{Publisher's Note}

Springer Nature remains neutral with regard to jurisdictional claims in published maps and institutional affiliations.

\section{Author details}

${ }^{1}$ Institute of Home and Food Sciences, Government College University Faisalabad, Punjab, Pakistan. ${ }^{2}$ School of Food Science and Biotechnology, Kyungpook National University, Daegu, South Korea. ${ }^{3}$ Department of Food Science and Human Nutrition, University of Veterinary and Animal Sciences, Lahore, Pakistan. ${ }^{4}$ College of Food and Agricultural Sciences, King Saud University, Riyadh, Saudi Arabia.

Received: 16 January 2017 Accepted: 24 May 2017

Published online: 08 June 2017

\section{References}

1. Sampaio GR, Saldanha T, Soares RAM, Torres EAFS. Effect of natural antioxidant combinations on lipid oxidation in cooked chicken meat during refrigerated storage. Food Chem. 2012;135(3):1383-90.

2. Kasapidou E, Wood JD, Richardson RI, Sinclair LA, Wilkinson RG, Enser M. Effect of vitamin E supplementation and diet on fatty acid composition and on meat colour and lipid oxidation of lamb leg steaks displayed in modified atmosphere packs. Meat Sci. 2012;90(4):908-16.

3. Jiang J, Xiong YL. Natural antioxidants as food and feed additives to promote health benefits and quality of meat products: A review. Meat Sci. 2016. Accepted.

4. Skřivan M, Marounek M, Englmaierová M, Skřivanová E. Influence of dietary vitamin $\mathrm{C}$ and selenium, alone and in combination, on the composition and oxidative stability of meat of broilers. Food Chem. 2012;130:660-4.

5. Rizzello CG, Cassone A, Coda R, Gobbetti M. Antifungal activity of sourdough fermented wheat germ used as an ingredient for bread making. Food Chem. 2011;127(3):952-9.

6. Brandolini A, Hidalgo A. Wheat germ: Not only a by-product. Int J Food Sci Nutr. 2012;63:71-4.

7. Gao J, Lin H, Wang XJ, Song ZG, Jiao HC. Vitamin E supplementation alleviates the oxidative stress induced by dexamethasone treatment and improves meat quality in broiler chickens. Poult Sci. 2010;89:318-27.

8. Liu RH. Whole grain phytochemicals and health. J Cereal Sci. 2007;46(3):207-19.

9. Packer $\mathrm{L}$, Witt EH, Tritschler HJ. Alpha-lipoic acid as a biological antioxidant. Free Radic Biol Med. 1995;19(2):227-50.

10. Shay KP, Moreau RF, Smith EJ, Smith AR, Hagen TM. Alpha-lipoic acid as a dietary supplement: molecular mechanisms and therapeutic potential. Biochimica et Biophysica Acta (BBA)-General Subjects. 2009;1790(10):1149-60.

11. Sohaib M, Anjum FM, Khan MI, Arshad MS, Shahid M. Enhancement of lipid stability of broiler breast meat and meat products fed on a-lipoic acid and a-tocopherol acetate supplemented feed. Lipids Health Dis. 2012;11:57.

12. Khan, M. I., Shehzad K, Arshad MS, Sehar A, Shabir MA, Saeed M: Impact of dietary a-lipoic acid on antioxidant potential of broiler thigh meat. J Chem. 2015. accepted. 
13. Guo ZY, Li JL, Zhang L, Jiang Y, Gao F, Zhou GH. Effects of alpha-lipoic acid supplementation in different stages on growth performance, antioxidant capacity and meat quality in broiler chickens. Br Poult Sci. 2014;55(5):635-43.

14. Senevirathne M, Kim SH, Siriwardhana N, Ha JH, Lee KW, Jeon YJ. Antioxidant potential of Ecklonia cava on reactive oxygen species sacenging, metal chelating, reducing power and lipoid peroxidation inhibition. Food Sci Tech. 2006;12:27-38.

15. Brand-Williams W, Cuvelier ME, Berset C. Use of a free radical method to evaluate antioxidant. Lebensm Wiss Technol. 1995:28:25-30.

16. Erel O. A novel automated direct measurement method for total antioxidant capacity using a new generation, more stable ABTS radical cation. Clin Biochem. 2004;37(4):277-85.

17. Arshad MS, Anjum FM, Khan MI, Shahid M. Wheat Germ Oil Enrichment in Broiler Feed With a-Lipoic Acid to Enhance the Antioxidant Potential and Lipid Stability of Meat. Lipids Health Dis. 2013b;12:164.

18. Perlo F, Bonato P, Teira G, Fabre R, Kueider S. Physicochemical and sensory properties of chicken nuggets with washed mechanically deboned chicken meat: Research note. Meat Sci. 2006;72(4):785-8.

19. Sallam Kl, Ishioroshi M, Samejima K. Antioxidant and antimicrobial effects of garlic in chicken sausage. LWT-Food Sci Tech. 2004;37(8):849-55.

20. Elgasim E, Al-Wesali M. Water activity and Hunter colour values of beef patties extended with Samh $(<\mathrm{i}>$ Mesembryanthemum forsskalei $</ i>$ Hochst) flour. Food Chem. 2000;69(2):181-5.

21. Cosenza G, Williams S, Johnson D, Sims C, Mcgowan C. Development and evaluation of a cabrito smoked sausage product. Meat Sci. 2003;64(2):119-24.

22. Cardoso CM, Mendes R, Nunes ML. Instrumental texture and sensory characteristics of cod frankfurter sausages. Int J Food Prop. 2009:12(3):625-43.

23. Liu F, Dai R, Zhu J, Li X. Optimizing color and lipid stability of beef patties with a mixture design incorporating with tea catechins, carnosine, and atocopherol. J Food Eng. 2010;98:170-7.

24. Shantha NC, Decker EA. Rapid, sensitive, iron-based spectrophotometric methods for determination of peroxide values of food lipids. J AOAC Int. 1994;77(2):421-4.

25. Satoh S, Toyo'oka T, Fukushima T, Inagaki S. Simultaneous determination of a-lipoic acid and its reduced form by high-performance liquid chromatography with fluorescence detection. J Chromatogr B. 2007;854(1): 109-15.

26. Asghar A, Lin C, Gray J, Buckley D, Booren A, Flegal C. Effects of Dietary Oils and a-Tocopherol Supplementation on Membranal Lipid Oxidation in Broiler Meat. J Food Sci. 1990;55(1):46-50.

27. Folch J, Lees M, Sloane-Stanley G. A simple method for the isolation and purification of total lipids from animal tissues. J Biol Chem. 1957;226:497-509.

28. Meilgaard M, Civille G, Carr B. Overall difference tests, Does a sensory difference exist between samples. Sen Eval Tech. 2007:463-104.

29. Steel R, Torrie J. Principles and procedures of statistics: a Biometrical approach MCGraw-Hill Book Company Toronto. Redvet. 2012;13(6):481

30. Kosińska A, Karamac M, Estrella I, Hernandez T, Bartolome B, Dykes GA. Phenolic compound profiles and antioxidant capacity of Persea americana Mill. peels and seeds of two varieties. J Agric Food Chem. 2012;60:4613-9.

31. Re R, Pellegrini N, Proteggente A, Pannala A, Yang M, Rice-Evans C. Antioxidant activity applying an improved ABTS radical cation decolorization assay. Free Radic Biol Med. 1999;26:1231-7.

32. Arshad MS, Anjum FM, Khan MI, Saeed F: Manipulation of natural antioxidants in feed to enhance the oxidative stability and quality of broiler breast meat and nuggets. J Food Process Preser. 2016. (Accepted).

33. Jung S, Choe JH, Kim B, Yun H, Kruk ZA, Jo C: Effect of dietary mixture of Gallic acid and linoleic acid on antioxidative potential and quality of breast meat from broilers. Meat Sci. 2010;86:520-526.

34. Selim NA, Nada SHA, Abdel-Sala AF, Youssef SF. Evaluation of some natural antioxidant sources in broiler diets. II. Effect on chemical and microbiological quality of chilled and frozen broiler meat. Int J Poult Sci. 2013;12:572-81.

35. Arshad MS, Anjum FM, Khan MI, Yasin M, Shahid M, El-Ghorab AH. Lipid Stability and Antioxidant Profile of Microsomal Fraction of Broiler Meat Enriched with a-Lipoic Acid and a-Tocopherol Acetate. J Agric Food Chem. 2011:59(13):7346-52

36. Yasin M, Asghar A, Anjum FM, Butt MS, Khan MI, Arshad MS, et al. Oxidative stability enhancement of broiler bird meats with a-lipoic acid and atocopherol acetate supplemented feed. Food Chem. 2012;131:768-73.

37. Parveen $\mathrm{R}$, Asghar A, Anjum FM, Khan Ml, Arshad MS, Yasmeen A. Selective deposition of dietary alpha-Lipoic acid in mitochondrial fraction and its synergistic effect with alpha-Tocoperhol acetate on broiler meat oxidative stability. Lip In Health Dis. 2013;12:52.

38. Mancini S, Preziuso G, Paci G. Effect of turmeric powder (Curcuma longa L.) and ascorbic acid on antioxidant capacity and oxidative status in rabbit burgers after cooking. World Rabbit Sci. 2016;24(2):121-7.

39. Banerjee R, Verma AK, Das AK, Rajkumar V, Shewalkar AA, Narkhede HP. Antioxidant effects of broccoli powder extract in goat meat nuggets. Meat Sci. 2012:91:179-84.

40. Guignot F, Touraille C, Ouali A, Renerre M, Monin G. Relationships between post-mortem $\mathrm{pH}$ changes and some traits of sensory quality in veal. Meat Sci. 1994:37:315-25.

41. Chidanandaiah KR, Sanyal MK. Effect of sodium alginate coating with preservatives on the quality of meat patties during refrigerated storage. J Muscle Foods. 2009;20:275-92.

42. Jay JM: Antioxidants. Modern food microbiology (4th Ed.). CBS Publishers and Distributors, New Delhi, India 1996, 265-266.

43. Sureshkumar S, Kalaikannan A, Dushyanthan K, Venkataramanujam V. Effect of nisin and butylated hydroxy anisole on storage stability of buffalo meat sausage. J Food Sci Technol. 2010;47(3):358-63.

44. Kumar D, Tanwar VK. Effects of incorporation of ground mustard on quality attributes of chicken nuggets. J Food Sci Technol. 2010;48(6):759-62.

45. Chandralekha S, Babu AJ, Moorthy PRS, Karthikeyan B. Studies on the Effect of Pomegranate Rind Powder Extract as Natural Antioxidant in Chicken Meat Balls During Refrigerated Storage. J Adv Vet Res. 2012;2:107-12.

46. Kala RK, Kondaiah N, Anjaneyulu ASR, Thomas R. Evaluation of quality of chicken emulsions stored at refrigeration for chicken patties. Int J Food Sci Technol. 2007;42:842-57.

47. Malav OP, Sharma BD, Kumar RR, Talukder S, Ahmed SR, Irshad A. Quality Characteristics and Storage Stability of Functional Mutton Patties Incorporated with Red Kidney Bean Powder. Ind J Small Rum. 2016;22(1):83-91.

48. Huff Lonergan E, Zhang W, Lonergan SM. Biochemistry of postmortem muscle; lessons on mechanisms of meat tenderization. Meat Sci. 2010;86(1):184-95.

49. Estévez M. Protein carbonyl in meat systems: A review. Meat Sci. 2011;89(3): 259-79.

50. Al-Hijazeen M, Lee EJ, Mendonca A, Ahn DU. Effect of Oregano Essential Oil (Origanum vulgare subsp. hirtum) on the Storage Stability and Quality Parameters of Ground Chicken Breast Meat. Antioxidants. 2016;5(2):18.

51. Nkukwana TT, Muchenje V, Masika PJ, Hoffman LC, Dzama K, Descalzo AM. Fatty acid composition and oxidative stability of breast meat from broiler chickens supplemented with Moringa oleifera leaf meal over a period of refrigeration. Food Chem. 2014(142):255-61.

52. Muchenje V, Dzama K, Chimonyo M, Strydom PE, Hugo A, Raats JG. Some biochemical aspects pertaining to beef eating quality and consumer health: A review. Food Chem. 2009;112(2):279-89.

53. Bonoli M, Caboni MF, Rodriguez-Estrada MT, Lercker G. Effect of feeding fat sources on the quality and composition of lipids of precooked ready-to-eat fried chicken patties. Food Chem. 2007;101(4):1327-37.

54. Arshad MS, Anjum FM, Khan MI, Shahid M: Wheat Germ Oil and a-Lipoic Acid predominantly improve the lipid profile of broiler meat. J Agric Food Chem. 2013a;61: 11158-11165.

55. Kandeepan G, Anjaneyulu ASR, Kondaiah N, Mendiratta SK. Quality of buffalo meat keema at different storage temperature. Afr J Food Sci. 2010;4:410-7.

56. Bhat ZF, Pathak V, Bhat HF. "Effect of refrigerated storage on the quality characteristics of microwave cooked chicken seekh kababs extended with different non-meat proteins", J Food Sci Technol. 2013a;50(5): 926-933.

57. Dashti NG, Mirlohi M, Dashti MG, Jafari M, Bahreini N: Antioxidant Effect of Thyme Essential Oil on Oxidative Stability of Chicken Nuggets. Int J Food Eng. 2015;1(2):115-20.

58. Thomas R, Anjaneyulu ASR, Kondaiah N. Quality and shelf life evaluation of emulsion and restructured buffalo meat nuggets at cold storage $\left(4^{\circ} \mathrm{C}\right)$. Meat Sci. 2006:72:373-9.

59. Bhat ZF, Pathak V, Bhat HF. Storage studies of chicken seekh kababs extended with different non-meat proteins. Fleischwirtschaft Int. 2011;1:87-91.

60. Malav OP, Sharma BD, Kumar RR, Talukder S, Ahmed SR. Antioxidant potential and quality characteristics of functional mutton patties incorporated with cabbage powder. Nutr Food Sci. 2015;45(4):542-63. 